\title{
The effect of ethanol blended diesel fuels on emissions from a diesel engine
}

\author{
Bang-Quan $\mathrm{He}^{\mathrm{a}, *}$, Shi-Jin Shuai ${ }^{\mathrm{a}}$, Jian-Xin Wang ${ }^{\mathrm{a}}$, Hong $\mathrm{He}^{\mathrm{b}}$ \\ ${ }^{a}$ State Key Laboratory of Automotive Safety and Energy, Tsinghua University, Beijing 100084, People's Republic of China \\ ${ }^{\mathrm{b}}$ Department of Air Chemistry and Air Pollution Control, Research Center for Eco-Environmental Sciences, \\ Chinese Academy of Sciences, Beijing 100085, People's Republic of China
}

Received 6 January 2003; accepted 6 August 2003

\begin{abstract}
The addition of ethanol to diesel fuel simultaneously decreases cetane number, high heating value, aromatics fractions and kinematic viscosity of ethanol blended diesel fuels and changes distillation temperatures. An additive used to keep the blends homogenous and stable, and an ignition improver, which can enhance cetane number of the blends, have favorable effects on the physicochemical properties related to ignition and combustion of the blends with $10 \%$ and $30 \%$ ethanol by volume.

The emission characteristics of five fuels were conducted on a diesel engine. At high loads, the blends reduce smoke significantly with a small penalty on $\mathrm{CO}$, acetaldehyde and unburned ethanol emissions compared to diesel fuel. $\mathrm{NO}_{x}$ and $\mathrm{CO}_{2}$ emissions of the blends are decreased somewhat. At low loads, the blends have slight effects on smoke reduction due to overall leaner mixture. With the aid of additive and ignition improver, CO, unburned ethanol and acetaldehyde emissions of the blends can be decreased moderately, even total hydrocarbon emissions are less than those of diesel fuel. The results indicate the potential of diesel reformation for clean combustion in diesel engines.
\end{abstract}

(C) 2003 Elsevier Ltd. All rights reserved.

Keywords: Diesel engine; Ethanol; Emission; Acetaldehyde; Additive; Ignition improver

\section{Introduction}

Increasing worldwide concern over combustion-related pollutants, such as particulate matter (PM), oxides of nitrogen $\left(\mathrm{NO}_{x}\right)$, carbon monoxide $(\mathrm{CO})$, total hydrocarbon (THC), acid rain, photochemical smog and depletion of the ozone layer, has led regulatory agencies to implement stringent emission regulations. Diesel engines are one of the major contributors to the pollutant emissions since they are widely used due to high combustion efficiency, reliability, adaptability and cost effectiveness. Soot and $\mathrm{NO}_{x}$ are formed during

\footnotetext{
*Corresponding author. Tel.: + 86-10-62772515; fax: + 8610-62785708.

E-mail addresses: hebq@tsinghua.edu.cn, hebangquan@tsinghua.org.cn (B.-Q.He), wangjx@tsinghua.edu.cn (J.-X. Wang).
}

diesel combustion, the required levels of $\mathrm{PM}, \mathrm{NO}_{x}$ are difficult to achieve through the improvement of combustion chamber and injection design. It is commonly accepted that clean combustion of diesel engines can be fulfilled only if engine development is coupled with diesel fuel reformulation. In the name of energy security, regional air quality, greenhouse gas emission reduction and even economic savings, oxygenated fuels were advocated to reduce particulate emissions (Liotta and Montalvo, 1993; Maricq et al., 1998). The reduction of particulate emissions due to the introduction of oxygenated compounds depends on the molecular structure, oxygen content of the fuel (Miyamoto et al., 1998; Kitamura et al., 2001) and local oxygen concentration in the fuel plume (Donahue and Foster, 2000).

Ethanol is a promising oxygenated fuel. Pure ethanol with additives such as cetane improver can sharply reduce particulates (Bechtold et al., 1991). At the early 
stage, poor fuel economy and low ignitability were the main barriers to apply ethanol fuel on diesel engines. Since late 1990s, ethanol blended diesel fuel has been used on heavy-duty and light-duty diesel engines in order to modify their emission characteristics. For example, the ethanol-diesel blends with $10 \%$ and $15 \%$ ethanol could reduce PM emissions by $20-27 \%$ and 30 $41 \%$, respectively (Spreen, 1999; Kass et al., 2001). The blends containing 83-94\% diesel fuel, 5-15\% ethanol, $1-3 \%$ additive and a small amount of commercially available cetane improver $(<0.33 \%$ by volume) in the mixture could reduce $41 \% \mathrm{PM}, 27 \% \mathrm{CO}$ emissions from a heavy-duty diesel engine in laboratory and field tests (Ahmed, 2001). However, ethanol diesel blends increase unburned hydrocarbons (Shih, 1998; Cole et al., 2001), $\mathrm{NO}_{x}$ emissions (Cole et al., 2001) and aldehyde emissions (Rideout et al., 1994; Gjirja et al., 1998). Moreover, the viscosity and lubricity of the blends decreases, cetane number linearly reduces at ambient temperature (Caro et al., 2001). Therefore, ignition improver and other additives are required to improve the durability and ignition of diesel engines when ethanol blended diesel fuels are used.

The potential of ethanol to reduce particulate emissions increases the flexibility to control $\mathrm{NO}_{x}$ emissions at different engine operating conditions. Higher THC emissions might offer reductant that regenerates $\mathrm{NO}_{x}$ adsorbers (Kass et al., 2001). Other environmental benefits associated with ethanol blended diesel fuel include the improvement of biodegradability and the reduction in net emissions of greenhouse gases if ethanol is produced from biomass.

In this study, a solvent additive was prepared to prevent ethanol blended diesel fuels from separating and an ignition improver was added in order to enhance cetane number of the blends. The properties of the blends with/without solvent additive and ignition improver were measured as a function of mixture composition. The effects of ethanol blended diesel fuels on distillation temperature, regulated emissions such as smoke, THC, $\mathrm{CO}, \mathrm{NO}_{x}$ and unregulated emissions including $\mathrm{CO}_{2}$, acetaldehyde and unburned ethanol were evaluated on a diesel engine.

\section{Experimental equipment and procedure}

\subsection{Equipment}

The engine used in this experiment was a four-cylinder direct injection diesel engine with a cylinder bore of $102 \mathrm{~mm}$, a stroke of $120 \mathrm{~mm}$ and a compression ratio of 17.5:1. The maximum torque was $245 \mathrm{Nm}$ at $1700 \mathrm{rpm}$ and the rated power was $59 \mathrm{~kW}$ at $2800 \mathrm{rpm}$. Tests were carried out only at $1700 \mathrm{rpm}$. To compare the emissions of various fuels used, the engine was not modified and its start of delivery was kept at $21^{\circ}$ crank angle before top dead center.

A Zöllner electric eddy dynamometer was coupled to the engine and measured the engine's power. Bosch smoke number was measured with a FBY-1 smoke analyzer.

Exhaust gases were measured on line by an AVL exhaust gas analyzer, in which THC was analyzed with a flame ionization detector (FID), $\mathrm{CO}$ and $\mathrm{CO}_{2}$ were analyzed with a non-dispersive infrared analyzer (NDIR), and $\mathrm{NO}_{x}$ was analyzed with a chemiluminescent detector (CLD). CO, THC, $\mathrm{CO}_{2}$ and $\mathrm{NO}_{x}$ emissions were average values of the acquired data at each steady-state operating condition. All the tests were repeated. The relative standard deviation of $\mathrm{NO}_{x}, \mathrm{CO}$, THC and $\mathrm{CO}_{2}$ concentration was $<1 \%,<5 \%,<3 \%$ and $<0.2 \%$, respectively. Acetaldehyde and unburned ethanol were quantitatively analyzed in a gas chromatograph/mass spectrometry with a PLOT-Q capillary column.

\subsection{Test procedure}

The engine was warmed up until the oil reached approximately $90^{\circ} \mathrm{C}$, and then loaded to the test points. The above emissions were begun to measure when coolant and exhaust temperatures reached equilibrium. During this time, RPM and torque were maintained constant. The engine was tested at six loads for each fuel at $1700 \mathrm{rpm}$. The highest loads of the blends with $30 \%$ vol ethanol were the maximum brake mean effective pressure (BMEP) that the engine could produce.

\section{Experimental results and discussion}

\subsection{The preparation of ethanol blended diesel fuels}

The solubility of ethanol in diesel is affected mainly by temperature, hydrocarbon composition of diesel and water content in the blend (Ecklund et al., 1984). With the increase of ethanol, soluble temperature increases and reaches the maximum when ethanol content is about $50 \%$ by volume, then decreases. For example, the blends with $20 \%$ ethanol and $50 \%$ ethanol will separate at about $0^{\circ} \mathrm{C}$ and $23^{\circ} \mathrm{C}$, respectively (Murayama et al., 1982). However, when ethanol-diesel phase is exposed to small amounts of water, the soluble temperature further increases under the same ethanol content. Usually, the separation of ethanol-diesel fuel can be prevented by emulsifiers, which can suspend small droplets of ethanol within diesel fuel, or co-solvents that acts as a bridging agent through molecular compatibility.

Based on the mechanism of emulsifiers and cosolvents, a solvent additive was synthesized according 
Table 1

Physicochemical properties of various fuels

\begin{tabular}{|c|c|c|c|c|c|c|}
\hline Items & Ethanol & E0 & E10 & E30 & E10AI & E30AI \\
\hline Density at $20^{\circ} \mathrm{C}(\mathrm{kg} / \mathrm{l})$ & 0.7893 & 0.8366 & 0.8308 & 0.8206 & 0.8324 & 0.8224 \\
\hline Aromatics, $\%(\mathrm{~m} / \mathrm{m})$ & - & 26.2 & 23.7 & 18.6 & 23.1 & 18.1 \\
\hline Kinematic viscosity at $20^{\circ} \mathrm{C}\left(\mathrm{mm}^{2} / \mathrm{s}\right)$ & - & 3.744 & 3.215 & - & 3.315 & 2.889 \\
\hline High heat value $(\mathrm{MJ} / \mathrm{kg})$ & 28.49 & 46.45 & 43.96 & 40.53 & 43.88 & 40.54 \\
\hline Cetane number & - & 50.1 & 44.2 & 25.5 & 48.7 & 45.8 \\
\hline $\mathrm{C}, \%(\mathrm{~m} / \mathrm{m})$ & 52.35 & 86.80 & 83.46 & 76.50 & 83.01 & 76.60 \\
\hline $\mathrm{H}, \%(\mathrm{~m} / \mathrm{m})$ & 13.25 & 13.20 & 13.15 & 13.09 & 13.08 & 13.11 \\
\hline $\mathrm{O}, \%(\mathrm{~m} / \mathrm{m})$ & 34.4 & 0.0 & 3.39 & 10.41 & 3.91 & 10.29 \\
\hline $\mathrm{C} / \mathrm{H}$ & 3.951 & 6.552 & 6.347 & 5.844 & 6.346 & 5.843 \\
\hline
\end{tabular}

to the following procedures: mix an unsaturated fatty acid, a polymer, xylene and tetrabutyl phthalate in the ratio of 3:1:0.45:0.15 by volume in a rotary evaporator, then vacumize them and keep them reacting at $70^{\circ} \mathrm{C}$ for $4 \mathrm{~h}$. Hereafter, add lecithin, whose volume is $2 \%$ that of the unsaturated fatty acid, to the reaction product. Finally, a yellow liquid additive, which did not contain any metals and $\mathrm{S}$ elements, was prepared.

Pure diesel fuel (E0) was used as a base fuel for ethanol-diesel blends in this study. The blends containing $10 \%$ and $30 \%$ ethanol fuel by volume were called E10 and E30, respectively. The ethanol fuel used contained $99.7 \%$ ethanol and $0.3 \%$ water by weight. The physicochemical properties of the three fuels above were shown in Table 1.

As shown in Table 1, cetane number of the blends decreases with ethanol content. The value of E30 reduces more significantly than that of E10. Both E10 and E30 are less than the minimum cetane number of Chinese diesel fuel standards, 45. Besides, the stability of the two blends is dependent on the composition of diesel, temperature, ethanol and water content. For E30, it only keeps stable for about $1 \mathrm{~h}$ at the temperature about $0^{\circ} \mathrm{C}$. In order to improve the stability and homogeneity of the blends and to enhance cetane number, a fuel, which contains $0.1 \%$ vol ignition improver (isooctyl nitrate), 2\% vol additives and 10\% vol ethanol fuel (E10AI), and a fuel with $1 \%$ vol ignition improver, $2 \%$ vol additives and 30\% vol ethanol fuel (E30AI) were prepared. E10AI and E30AI are stable even when the blends contain $2 \%$ vol water at the temperature below $0^{\circ} \mathrm{C}$. The physicochemical properties of E10AI and E30AI were also shown in Table 1.

As the proportion of ethanol in the blends increases, oxygen content increases and aromatics fractions decreases, but viscosity, density and high heat value lower. It is also seen that additive and ignition improver can slightly restore the viscosity of the blends, and increase the cetane number of E10AI and E30AI to 48.7 and 45.8, respectively, which can ensure good cold starting, reduced noise and long durability for diesel engines.

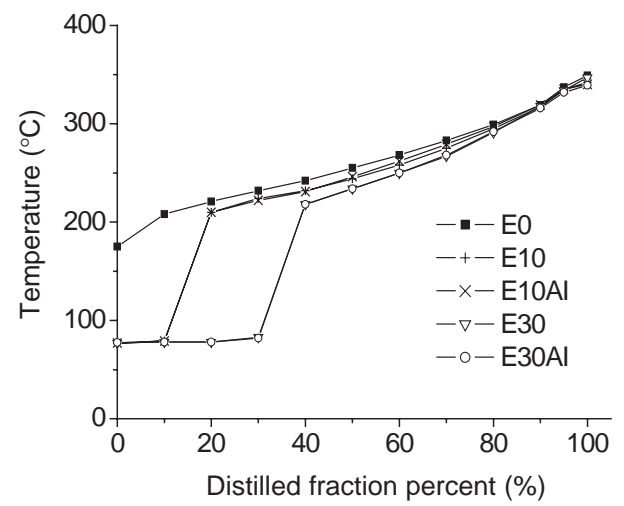

Fig. 1. Distillation curves.

As shown in Fig. 1, the use of ethanol to diesel fuel modifies the shape of distillation curves at the temperatures below $200^{\circ} \mathrm{C}$. The greater the ethanol content in the blends, the higher the volatility is. The distillation curves of the blends with/without the additive and ignition improver only alter slightly at the same ethanol content. However, all the blends satisfy the specifications as regards the distilled volume fractions.

\subsection{Regulated engine emissions}

Smoke is a kind of aerosol and has close relations with PM emissions. As shown in Fig. 2, the influence of the fuels used on smoke varies with engine conditions and ethanol content. At low loads, the blends have slight effect on Bosch smoke due to low flame temperature and overall leaner mixture. At high loads, smoke is higher, but the suppression of ethanol to smoke is stronger. For instance, Bosch smoke number of E0, E10AI and E30AI at $0.58 \mathrm{MPa}$ BMEP is $1.6,1.5$ and 0.9 , respectively. Compared to E0, the reduction in smoke is $6.3 \%$ for E10AI and $43.8 \%$ for E30AI. The reduced smoke at high loads can be explained by the following reasons: (1) a very fuel-rich core exists at high loads because of relatively long injection period, but with the use of ethanol, an oxidizer is effectively introduced to the 


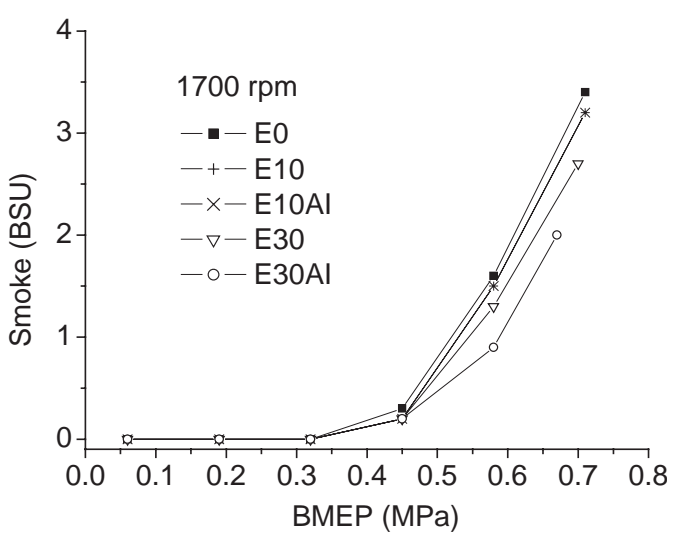

Fig. 2. Comparison of Bosch smoke number between various fuels.

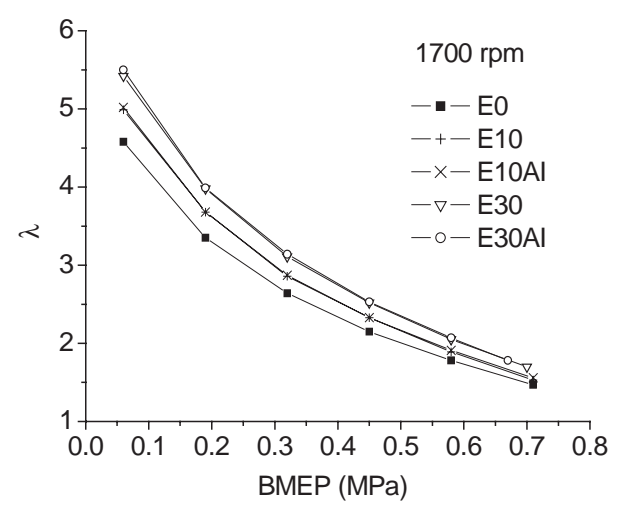

Fig. 3. The relationship between $\lambda$ and BMEP.

fuel-rich regions and suppress soot formation in combustion chamber (Choi and Reitz, 1999; He et al., 2003); (2) ethanol does not provide the initial radicals for the formation of aromatic rings (Gjirja et al., 1998); (3) high oxygen content of the blends combined with low $\mathrm{C} / \mathrm{H}$ ratio and aromatics fractions contributes to the reduction of smoke; (4) high excess air ratio $(\lambda)$ shown in Fig. 3 results in overall leaner mixture. The smoke number of E10AI and E10 is almost the same under all operating conditions, which means that the additive and ignition improver have slight effect on smoke emissions in this condition. However, E30AI is more effective in reducing smoke than E30 at high loads, which can be attributed to improved combustion due to the addition of additive and ignition improver.

In the case of $\mathrm{NO}_{x}$ emissions shown in Fig. 4, the emissions of the blends decrease with ethanol content at the same loads. The reduction of $\mathrm{NO}_{x}$ at high loads is clear. This reduced tendency of $\mathrm{NO}_{x}$ was also reported (Ahmed, 2001; Caro et al., 2001). Since latent heat of vaporization of ethanol is high and heat value of the blends is low, the higher the load, the more the fuel

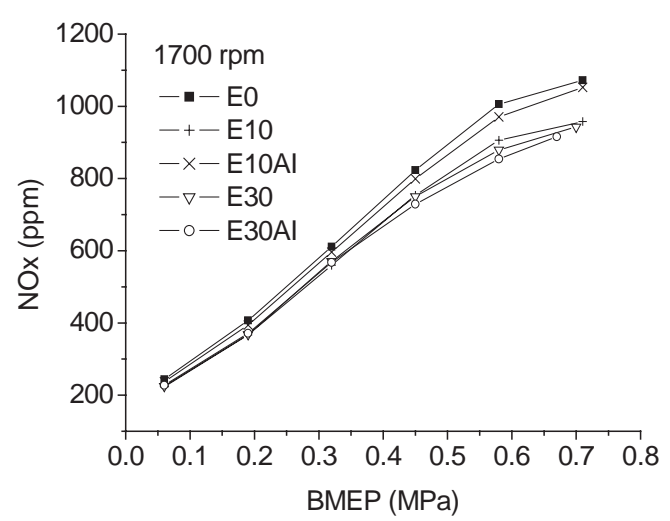

Fig. 4. Comparison of $\mathrm{NO}_{x}$ emissions between various fuels.

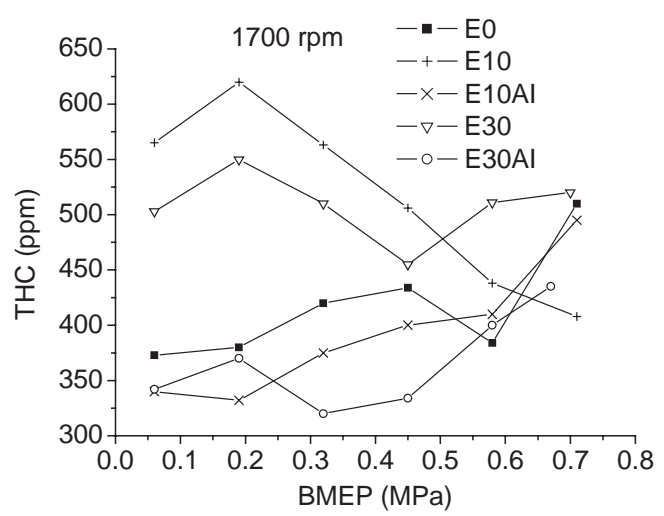

Fig. 5. Comparison of THC emissions between various fuels.

injected is. Consequently, cylinder charge temperature and combustion temperature abate, $\mathrm{NO}_{x}$ emissions diminish. Trace amount of water in the blends can help to suppress the formation of thermal NO (Kadota and Yamasaki, 2002). With respect to E10 and E10AI or E30 and E30AI, the additive and ignition improver have different impacts on $\mathrm{NO}_{x}$ emissions, which might correlate with inhomogeneity and combustion of the blends.

THC emissions of different fuels are shown in Fig. 5. Compared to E0, E10 and E30 emit more THC emissions at most operating conditions. One reason is that high latent heat of vaporization of ethanol tends to produce slow vaporization and mixing of fuel and air. Inhomogeneity of the blends may also contribute to leaner mixture in some regions of combustion chamber and results in more unburned fuels in combustion process. High THC emissions were observed by Shih (1998). However, when the additive and ignition improver are used, THC emissions of E10AI and E30AI reduce to quite a low level and even are less than those of E0 in most cases. Homogeneity of E10AI and E30AI 


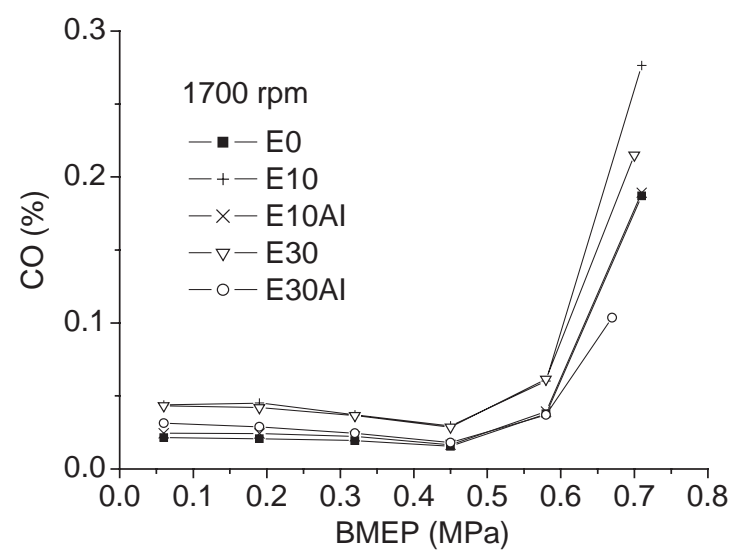

Fig. 6. Comparison of $\mathrm{CO}$ emissions between various fuels.

and increased oxidation of combustion intermediates by the use of additive and ignition improver would be expected to be the main reasons for THC reduction in this engine control system.

Fig. 6 shows $\mathrm{CO}$ emission characteristics when various fuels were used. It is clear that $\mathrm{CO}$ emissions of the blends are higher than those of E0 except E30AI at high loads, and increase with ethanol. High CO emissions of the blends can be explained by the fact that low combustion temperature throughout the cycle and thick quenching layer caused by high latent heat of ethanol result in low oxidation rate of $\mathrm{CO}$. But with the use of additive and ignition improver, $\mathrm{CO}$ emissions of E10AI and E30AI can be moderately decreased, which would contribute to the increased oxidation of $\mathrm{CO}$ promoted by the additive and ignition improver.

\subsection{Unregulated engine emissions}

$\mathrm{CO}_{2}$ is a greenhouse gas and will be limited in many countries. As shown in Fig. 7, $\mathrm{CO}_{2}$ emissions decrease with the increase of ethanol in the blends. The main reason of $\mathrm{CO}_{2}$ reduction is low $\mathrm{C} / \mathrm{H}$ ratio and high oxygen content of the blends.

Fig. 8 depicts acetaldehyde emissions when various fuels are used. Although acetaldehyde emissions are formed under different operating conditions, the emissions are very low relative to THC emissions. With the increase of ethanol content, acetaldehyde emissions increase. Since acetaldehyde is an intermediate product from the quenched fuel of partial oxidation (Faiz et al., 1996), maybe more acetaldehyde emissions are converted from ethanol under those operating conditions. It is also seen that acetaldehyde emissions have close relations with loads and ethanol content. With the increase of loads, acetaldehyde emissions gradually decrease to their minima at medium loads, then increase again at high loads. High acetaldehyde emissions are

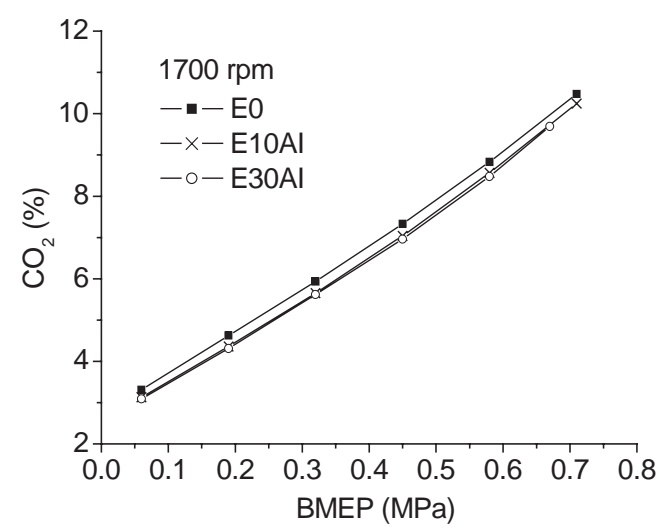

Fig. 7. The relationship between $\mathrm{CO}_{2}$ and BMEP.

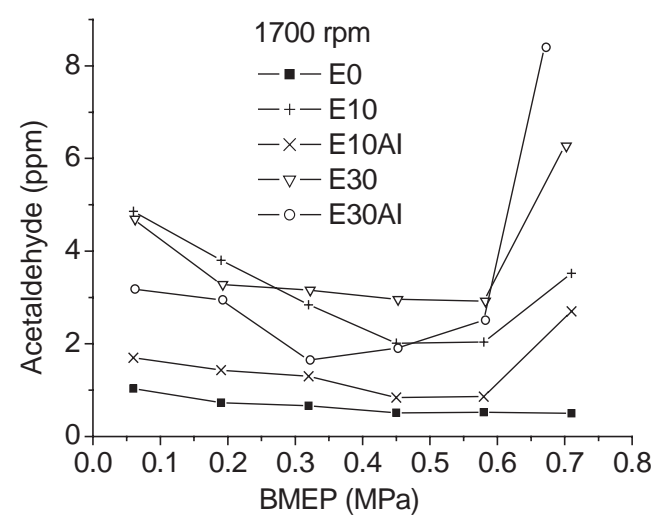

Fig. 8. Comparison of acetaldehyde emissions between various fuels.

attributed to thick quenching layer caused by a large amount of ethanol fuel at high loads and to low oxidation rate of acetaldehyde at low loads due to low combustion temperatures and exhaust temperatures (Fig. 9).

Comparing E10 with E10AI, E10 emits more acetaldehyde emissions than E10AI at the same operating conditions, which means that the additive and ignition improver can improve combustion. The similar tendency of acetaldehyde emissions between E30 and E30AI is found except high loads.

As shown in Fig. 10, it is evident that there are unburned ethanol emissions at all operating conditions when the blends are used. With the increase of ethanol, unburned ethanol emissions of the blends enhance and reach maxima at certain medium loads dependent on ethanol content, which indicates that unburned ethanol oxidizes less when pushed out from combustion chamber. Comparing E10 with E10AI, unburned ethanol of E10 is higher than that of E10AI, which is attributed to inhomogeneity of E10. The similar 


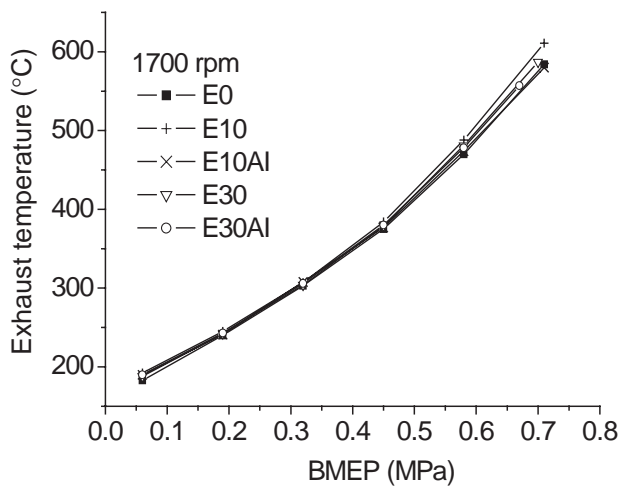

Fig. 9. Exhaust temperatures.

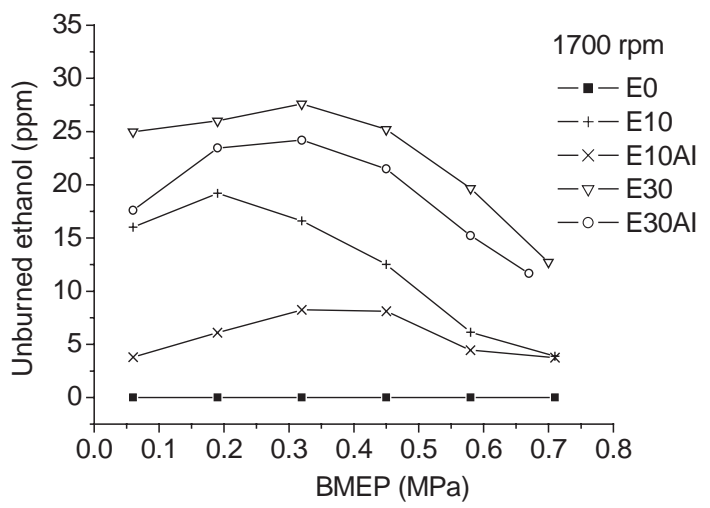

Fig. 10. Comparison of unburned ethanol emissions between various fuels.

relationship of unburned ethanol emissions between E30 and E30AI is found.

\section{Conclusions}

The addition of ethanol to diesel fuel changes the physicochemical properties of the blends. With the increase of ethanol, density, cetane number, kinematic viscosity, high heat value and aromatics fractions of the blends decrease. Distillation temperatures also change. Additive can enhance the stability of ethanol blended diesel fuel, and partly restore their viscosity. Ignition improver is needed to enhance their cetane number.

The impacts of ethanol on emissions vary with engine operating conditions, ethanol content, additive and ignition improver. At high load conditions, ethanol blended diesel fuels have stronger effects on smoke, $\mathrm{NO}_{x}$, acetaldehyde emissions and unburned ethanol emissions. With the increase of ethanol, smoke, $\mathrm{NO}_{x}$ and $\mathrm{CO}_{2}$ emissions decrease, $\mathrm{CO}$, acetaldehyde emissions and unburned ethanol emissions increase at most operating conditions. At low loads, the blends have slight effects on smoke reduction. With the utilization of additive and ignition improver, $\mathrm{CO}$, acetaldehyde and unburned emissions can be moderately decreased, and THC emissions are significantly reduced and even are less than those of E0 at low loads.

\section{Acknowledgements}

This study was financially supported by Hi-Tech Research and Development Program of China in the program of "Integration and Optimization of $\mathrm{NO}_{x}$ Reduction Catalysts and Diesel Engines" under contract 2001AA64304003, and by Tsinghua University in the program of "New Concept Design Based on Oxygenated Bio-fuel for Automobiles" under contract Jz2002002.

\section{References}

Ahmed, I., 2001. Oxygenated diesel: emissions and performance characteristics of ethanol-diesel blends in CI engines. SAE Technical Paper Series 2001-01-2475.

Bechtold, R.L., Timbario, T.J., Miller, M.T., Urban, C., 1991. Performance and emissions of a DDC 8V-71 transit bus engine using ignition-improved methanol and ethanol. SAE Technical Paper Series 912356.

Caro, P.S., Moulounguia, Z., Vaitilingomb, G., Berge, J.C., 2001. Interest of combining an additive with diesel-ethanol blends for use in diesel engines. Fuel 80, 565-574.

Choi, C.Y., Reitz, R.D., 1999. An experimental study on the effects of oxygenated fuel blends and multiple injection strategies on DI diesel engine emissions. Fuel 78, 1303-1317.

Cole, R.L., Poola, B., Sekar, R., Schaus, J.E., Mcpartlin, P., 2001. Effects of ethanol additives on diesel particulate and $\mathrm{NO}_{x}$ emissions. SAE Technical Paper Series 2001-01-1937.

Donahue, R.J., Foster, D.E., 2000. Effects of oxygen enhancement on the emissions from a DI diesel via manipulation of fuels and combustion chamber gas composition. SAE Technical Paper Series 2000-01-0512.

Ecklund, E.E., Bechtold, R.L., Timbario, T.J., McCallum, P.W., 1984. State-of the-art report on the use of alcohols in diesel engines. SAE Transactions 840118, 684-702.

Faiz, A., Weaver, C.S., Walsh, M.P., 1996. Air Pollution from Motor Vehicles - Standards and Technologies for Controlling Emissions. The International Bank for reconstruction and development/The World Bank, USA.

Gjirja, S., Olsson, E., Kariström, A., 1998. Considerations on engine design and fuelling technique effects on qualitative combustion in alcohol diesel engines. SAE Technical Paper Series 982530.

He, B.Q., Wang, J.X., Yan, X.G., Tian, X., Chen, H., 2003. Study on combustion and emission characteristics of diesel engines using ethanol blended diesel fuels. SAE Technical Paper Series 2003-01-0762.

Kadota, T., yamasaki, H., 2002. Recent advances in the combustion of water fuel emulsion. Progress in Energy and Combustion Science 28, 385-404. 
Kass, M.D., Thomas, J.F., Storey, J. M., Domingo, N., Wade, J., Kenreck, G., 2001. Emissions from a 5.91 diesel engine fueled with ethanol diesel blends. SAE Technical Paper Series 2001-01-2018.

Kitamura, T., Ito, T., Senda, J., Fujimoto, H., 2001. Extraction of the suppression effects of oxygenated fuels on soot formation using a detailed chemical kinetic model. JSAE Review 22, 139-145.

Liotta, J.F.J., Montalvo, D.M., 1993. The effect of oxygenated fuels on emissions from a modern heavy-duty diesel engine. SAE Technical Paper Series 932734.

Maricq, M.M., Chase, R.E., Podsiadlik, D.H., Siegl, W.O., Kaiser, E.W., 1998. The effect of dimethoxy methane additive on diesel vehicle particulate emissions. SAE Technical Paper Series 982572.

Miyamoto, N., Ogawa, H., Nurun, N.M., Obata, K., Arima, T., 1998. Smokeless, low $\mathrm{NO}_{x}$ high thermal efficiency and low noise diesel combustion with oxygenated agents as main fuel. SAE Technical Paper Series 980506.

Murayama, T., Miyamoto, N., Yamada, T., Kawashima, J., Itow, K., 1982. A method to improve the solubility and combustion characteristics of alcohol-diesel fuel blends. SAE Technical Paper Series 821113.

Rideout, G., Kirshenbhaltt, M., Prakash, C., 1994. Emissions from methanol, ethanol and diesel powered transit buses. SAE Technical Paper Series 942261.

Shih, L.K., 1998. Comparison of the effects of various fuel additives on the diesel engine emissions. SAE Technical Paper Series 982573.

Spreen, K., 1999. Evaluation of oxygenated diesel fuels. Final Report for Pure Energy Corporation Prepared at Southwest Research Institute, San Antonio, TX. 